\title{
Good grades, but who gets the cash?
}

\section{Britain's Research Assessment Exercise finds excellence more widespread than a focus on elite institutions would suggest.}

British universities are bubbling with speculation about how the annual $£ 1.5$ billion (US $\$ 2.2$ billion) in government funding for research will be distributed, following the nation's most extensive audit of research quality.

Of the 52,400 academic researchers from 159 universities that entered the Research Assessment Exercise (RAE), published on 18 December, $17 \%$ were regarded as world-leading $\left(\right.$ rated $4^{*}$ ), and $37 \%$ as internationally excellent $\left(\right.$ rated $\left.3^{*}\right)$. These results will largely determine the way that higher-education funding councils allocate the money in the academic years spanning 2009-14. But universities will have to wait until 4 March 2009 to find out exactly how the results translate into cash.

The British government and the funding councils have long maintained a policy concentrating funding on the best research. Departments with high ratings are usually awarded more money per volume of staff than those with lower ranks, with funds divided according to an algorithm drawn up by the funding councils of England, Scotland and Wales. This has traditionally resulted in the same 25 or so institutions winning around $80 \%$ of the available funding, a situation that is unlikely to change this time round, according to one former vice-chancellor of a research-intensive university.

But the latest RAE results show that highly rated research is spread much more widely than that core of 25. Forty-nine universities had at least some $4^{*}$ research in their submissions, and at least half of the submissions from 118 universities were rated $4^{*}$ or $3^{*}$. This raises fears that the funding will be spread too thinly — or that some top-quality research will not be supported. "This could seriously erode Britain's position as a world leader, particularly in biomedical sciences, in which the United Kingdom is second only to the United States," says Steve Smith, principal of the faculty of medicine at Imperial College London.

Concentrating the funding at the top will also leave little cash for the next class of research, designated as internationally recognized $\left(2^{\star}\right)$, forcing funding councils to choose between their commitment to reward excellence wherever it is found, and selectively targeting their research money. "I don't think they can do both, and they now have a big problem," the former vice-chancellor says.

"The policy is to fund the best properly and then see what is left for the rest," confirms a source connected to previous RAEs. He anticipates that $2^{*}$ work will receive at least some funding - there would be a great backlash otherwise, he says - but "my suspicion is that the money will certainly run out before $1^{*}$ [nationally recognized work]," he says.

Work submitted to the RAE is judged by peer review, using experts from many countries to ensure robust quality comparisons with the rest of the world. However, the RAE does not directly compare UK researchers or institutions against their overseas competitors. William Schowalter, a chemical engineer from Princeton University in New Jersey and one of the RAE's international judges, says that he is "convinced" the benchmarks were set appropriately.

"We can be confident that the results are consistent with other benchmarks indicating that the United Kingdom holds second place globally to the United States in significant subject fields," says David Eastwood, chief executive of the Higher Education Funding Council for England (HEFCE), which runs the RAE.

Nature analysed RAE data on the top-performing universities in four key disciplines (see graph). The University of Cambridge ranked highest in both physics and biological sciences. And in chemistry, $40 \%$ of the university's submissions achieved a $4^{\star}$ grade $-10 \%$ more than its nearest rival.

Of the four subjects, physics had the broadest distribution of top-quality research, with 16 departments awarded $4^{\star}$ for $20 \%$ or more of their submissions. And biological-science departments made more RAE submissions than any other subject, with five universities including Leeds, Manchester and Cambridge - submitting more than 100 academics for assessment.

This year's RAE is the sixth and final exercise of its kind to be run in Britain. The government decided in 2006 to replace it with the Research Excellence Framework, which will rely more heavily on metrics such as publication citations to judge the quality of research. The move has been prompted by the expense and administrative burden that peer review places on institutions: the 2008 assessment cost HEFCE $£ 12$ million to run, more than twice as much as the previous RAE in 2001.

The changes will be closely watched by other nations that already use, or are in the process of implementing, similar research assessment systems, including Hong Kong, Australia and New Zealand.

A spokesman from Hong Kong's University Grants Committee, which allocates funding on the basis of the region's own RAE, told Nature that it is "conscious of the burden the RAE places on institutions". The committee is already consulting academic institutions about the assessment process, and "one of the factors we shall take into account is the release of the UK RAE [2008 results] and the reaction to it, as well as further developments in the metrics model the United Kingdom is moving towards".

\section{Natasha Gilbert}

See Editorial, page 7.

\section{TOP OF THE CLASS}

The number of staff judged 'world leading' (4*) or 'internationally excellent' $\left(3^{\star}\right)$ by the 2008

Research Assessment Exercise, at the leading UK universities in four core subject areas

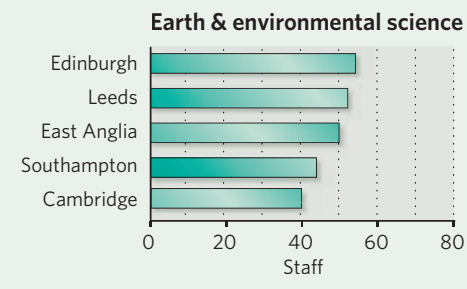

Chemistry

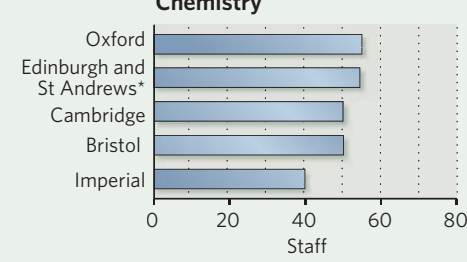

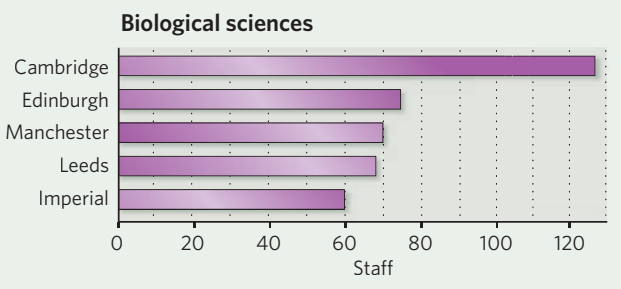

Physics

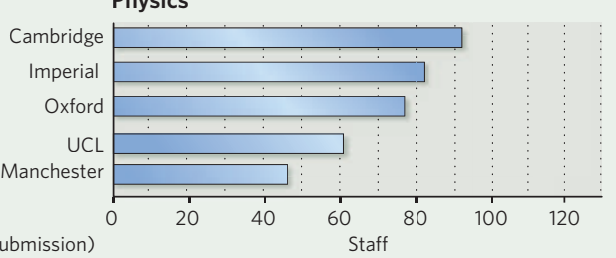


visa applications for foreign researchers and give international science and engineering students an automatic one-year visa extension to seek work or advanced study.

\section{Suspended urologist set to return to Austrian university}

The urologist at the centre of Austria's biggest-ever research scandal can return to work at the Medical University of Innsbruck, a disciplinary committee has ruled.

Hannes Strasser was suspended from clinical, teaching and research duties in September 2008 following accusations of malpractice in a clinical trial using stem cells to treat urinary incontinence (see Nature 454, 922; 2008).

The national disciplinary committee responsible for university staff has now concluded that the suspension was not legally justified, as more than three years had passed since the alleged misdemeanour occurred.

Strasser, who is facing criminal charges relating to harming patients or putting them at risk of harm, is on paid leave until the end of January. He will not be allowed to treat patients until the criminal case is resolved - which is likely to take at least a year. An investigation by the Austrian National Academy of Sciences is also ongoing.

\section{Coal conversion plant fires up in China}

China's first coal-liquefaction plant is up and running. Located in Inner Mongolia, the facility is run by the state-owned Shenhua Group.

According to a statement issued by Shenhua last week, the plant has been turning coal into liquid fuel and chemical products since December. The technique, which is also widely used in South Africa, has been criticized for its high emissions of carbon dioxide.

Last year, the Chinese government issued a moratorium on new coal-liquefaction facilities, but allowed Shenhua to complete its Mongolia plant and continue work on a second. The company says it is developing ways to capture and store the $\mathrm{CO}_{2}$ emitted during the process.

\section{Italian universities lose freedom to appoint staff}

Italian universities will have little say in choosing their own professors thanks to a law approved by parliament last week.

According to the new rules, a five-person selection committee will oversee each appointment. But a university recruiting a professor can appoint only one member to the board. The other four members will be picked at random from a list of twelve voted for by the relevant community of scientists across Italy.

The existing concorsi system is similar, but it allowed universities to have more control over selection - a privilege that was sometimes abused to make appointments based on local politics rather than on merit. Many academics had lobbied for a reform that would allow universities to make their own free choice, but lose funds if their chosen professors underperformed.

\section{Corrections}

The News round-up item 'Biodiversity gets catalogued online' (Nature 456, 844-845; 2008) gave incorrect funding numbers for the Encyclopedia of Life. The total budget for the project's first five years is US\$50 million; $\$ 2.5$ million came from the Sloan Foundation and $\$ 10$ million from the MacArthur Foundation in 2007

The News story 'Good grades, but who gets the cash?' (Nature 457, 13; 2009) incorrectly calculated the number of staff submitted by the University of Oxford who were rated world-leading and internationally excellent in the biological-sciences category of the 2008 Research Assessment Exercise. The correct number is 75 , putting the university in second place behind the University of Cambridge. 